\title{
Effects of Career Interventions on Vocational Cognitive Complexity
}

\author{
Wei-Cheng Mau, Christy Calvert, Richard Gregory
}

Career development can be viewed as an ongoing restructuring of vocational schemas,
proceeding from a state of undifferentiation to a state of increasingly differentiated, articulated,
and hierarchically integrated vocational constructs (Werner, 1957). As individuals gain relevant
occupational experience, they begin to differentiate more complex schemas for construing various
vocations, and to integrate these into an increasingly cohesive and comprehensive system of under-
standing (Tiedeman \& O'Hara, 1963). The present study examined the extent to which career interventions affect cognitive development in vocational schemas.

Vocational cognitive complexity is comprised of vocational construct differentiation and vocational construct integration. Vocational construct differentiation is the ability to distinguish among many vocational constructs, whereas vocational construct integration represents the ability to assimilate constructs into a cohesive cognitive schema. Borrowing from Landfield's (1977) developmental model of vocational structure, Neimeyer (1988) conceptualized vocational construct differentiation and vocational construct integration as two independent dimensions. These two independent dimensions are used to construct four stages of career development ranging from low differentiation and low integration of structures (stage 1), to low construct differentiation and high construct integration (stage 2), to high construct differentiation and low construct integration (stage 3), to high construct differentiation and high construct integration (stage 4), the most ad-vanced stage.

Correlational studies have linked vocational cognitive complexity with various career behaviors. For example, vocational cognitive complexity has been found to be associated with career decidedness and career exploratory behavior (Neimeyer, Nevill, Probert, \& Fukuyama, 1985), interest crystallization (Winer \& Gati, 1986), appropriate vocational choices (Bodden, 1970; Bodden \& Klein, 1972), rational career decision making (Kortas, Neimeyer, \& Prichard, 1992), and career decisionmaking efficacy (Nevill, Neimeyer, Probert, \& Fukuyama, 1986). However, little effort has been devoted to investigating the effects of career interventions on vocational cognitive complexity.

Gender difference in vocational cognitive complexity has been a matter of great interest among researchers (Bodden, 1970; Cochran, 1983; Neimeyer, 1988; Neimeyer, Metzler, \& Bowman, 1988; Parr \& Neimeyer, 1994). Studies have consistently shown that men exhibit higher construct differentiation (i.e., Bodden, 1970), whereas women have higher construct integration (i.e., Cochran, 1983). However, research has not indicated if different career interventions impact men and women differently in terms of vocational cognitive complexity. Therefore, this study was also interested in examining the possibility of interaction between gender and treatments.

The purpose of this study was to investigate the effects of different career interventions on vocational construct differentiation and integration. Specifically, this study attempted to determine if the voca-tional cognitive complexity of college students as measured by the Career Grid procedure, which is described in the methods section, would be affected by the utilization of Vocational Card Sort (VCS), SelfDirected Search (SOS), or System of Interactive Guidance and Information Plus (SIGI+).

VCS is primarily exploration-oriented with an emphasis on value articulation, SOS is explorationoriented based on interests, and SIGI+ is a value-based occupational information system. Due to the exploratory nature of the VCS, SOS, and SIGI+ interventions, it was expected that these treatment groups would significantly increase occupational options compared to the control group. Because both VCS and SIGI+ require subjects to examine their important constructs explicitly, it was expected that these two interventions would have a greater impact on the vocational cognitive complexity of participants than the control group. In addition to the cognitive complexity mea-sures, participants' subjective evaluation on 
the use of the treatment programs were also examined. Both SDS and SIGI + are very self-directed with little counselor interaction, whereas the nature of VCS requires a high level of counselor interaction. This study was interested in determining whether a student's satisfaction with an intervention program is a function of counselor involvement.

\section{Methods}

Sample

First-year college students enrolled in the Wellness I class at a small, private, four-year liberal arts college were solicited. Of the 142 enrolled, 121 students (55 men and 66 women) participated in this study. The other 21 students were excluded from this study because they either did not grant permission for using their assessment data or did not complete the assignment within the scheduled time. The sample consisted mostly of traditional-aged white students. The average age was 18.5 , with a standard deviation of 1. 7. Career exploration is a component ( $10 \%$ of the grade) of the Wellness I class, a required course for all freshmen which examines the educational, physical, interpersonal, spiritual, and occupational well-being of individuals. The career exploration segment was used to conduct the research for this study. Other course content has no direct relevance to career activities.

\section{Procedure}

Students who participated in this study were randomly assigned to one of four groups: (1) VCS, (2) SDS, (3) SIGI+, and (4) a wait-listed control group. Each participant made an appointment to see the ca-reer counselor in the Career Planning Office. On the basis of the random assignments, the career counselor administered the designated treatment to each participant individually. The student participant then completed a set of outcome measures immediately after finish-ing the assigned treatment. The average time for each treatment ses-sion was 79 minutes (VCS; ranged from 55 to 95 minutes), 74 minutes (SDS; ranged from 45 to 110 minutes), or 74 minutes (SIGI+; ranged from 50-120 minutes). Students in the wait-listed control group were administered the treatment of their choice after they completed all of the outcome measures. All treatments were administered by an experienced masters-level career counselor.

\section{Treatments}

\section{Vocational Card Sort}

The content and procedure of the Vocational Card Sort treatment used in this study approximated Dolliver's (1967) card sort technique. The card sort consists of 36 representative occupations that have been selected to represent Holland's (1985) six occupational types. During the individual sessions, participants were instructed to sort the cards into three stacks: "might choose," "would not choose," and "in question." Participants were asked to add any other occupations they liked that were not included in the deck. The counselor then asked participants to re-examine the "in question" stack, offering information to clarify any questions participants had. Based on the new information, participants sorted the cards in the "in question" stack into either the "might choose" stack or the "would not choose" stack. Participants were then instructed to sort the "would not choose" stack into groups based on their perceived similarities or differences among these occupations. The number of groups to be sorted was not pre-imposed. Participants were required to verbalize their reasoning when sorting cards into groups. This procedure was repeated for sorting the "might choose" stack. Participants were then instructed to rank the occupations in the "might choose" stack according to their preference. Since each card contains a Holland occupational code, occupations with the same Holland code were explored by the participant with the counselor's assistance using the Dictionary of Holland Occupational Codes. Participants were also encouraged to search for specific information in the Dictionary of Occupational Titles (DOT), which was available to them during the session. 


\section{Self-Directed Search}

Self-Directed Search (Form R; Holland, 1994) is a self-administered, self-scored, and selfinterpreted career counseling tool. It is designed to stimulate exploratory behavior and to increase career options under consideration. The inventory yields a three-letter code that can be used to explore similar occupations in the Occupational Finder. Included with SDS is a booklet, entitled "You and Your Career," which is designed to help individuals understand Holland's (1985) typologies-Realistic, Investigative, Artistic, Social, Enterprising, and Conventional. After participants in this study completed the SDS, the derived three-letter code was explained by the counselor individually. Occupations classified under the derived Holland code were explored, and participants were also encouraged to search for further information from the DOT.

\section{The System of Interactive Guidance and Information Plus}

The System of Interactive Guidance and Information Plus (Educational Testing Service, 1994) covers the major aspects of career decision-making via nine separate modules: (1) introduction, (2) selfas-sessment, (3) search, (4) information, (5) skills, (6) preparing, (7) coping, (8) deciding, and (9) next steps. Each module provides an array of interactive activities that can be used selectively or entirely. The philosophical basis for SIGI+ proposes that value identification and clarification are basic to an effective career decision-making process, which will involve evaluation of rewards, routines, and require-ments that accompany each choice. In this study, the counselor provided an overview of the SIGI+ program for participants. The participants were then instructed to complete the self-assessment and search modules of the program. They were instructed to print the summary page of their selfassessment and the list of occupations generated from the search section. After participants completed the modules, the counselor discussed the results and the possible plans of action with each participant individually.

Instrumentoandthemersurswere used in this study to assess treatment outcomes, and are described as follows:

The Career Grid. The Career Grid (Mau, 1997) consists of a $10 \times 10$ matrix in which as many as 10 occupations are rated in terms of a set of 10 supplied value constructs using a 3-point Likert-type scale (1 as unlikely, 2 as likely, and 3 as very likely). The grid is a modification of Bodden's (1970) Cognitive Differentiation Grid. Several measures can be ob-tained from the Career Grid, which vary from such simple descriptive statistics as the percentage of positive ratings in the matrix, to relatively complex cluster or principle component analyses (see Brook, 1992; and Cochran, 1983). Computer software has also been developed for various scoring methods (e.g., Chambers \& Grice, 1986; Landfield \& Schmittdiel, 1983; Sewell, Mitterer, Adams-Webber, \& Cromwell, 1991). Three measures-vocational construct integration, vocational construct differentiation, and number of occupations used were scored.

Construct integration. This measure indicates the overall strength of correlation among all construct ratings in the matrix, reflecting the level of integration of vocational constructs (Adams-Webber, 1979). The construct integration measure was obtained by calculating the product-moment correlations between each pair of value constructs. Each correlation coefficient was squared and summed. This scoring procedure has been widely used to compute construct integration (Cochran, 1983; Mau, 1997; Slater, 1977). Integration scores range from 0 (low integration) to 45 (high integration). Test-retest reliability (1 month), based on 82 university students, was .94 (Feixas, Moliner, Montes, Mari, \& Neimeyer, 1992).

Construct differentiation. Construct differentiation is considered to be one of the most important factors in career decision-making (Cochran, 1983). If a construct does not allow clear differentiation in ratings, it is useless for decision-making, regardless of how important one thinks it is. Individuals who manifest high construct differentiation are capable of discriminating among occupational constructs, whereas low construct differentiation individuals are said to have difficulty in discriminating among 
constructs. Standard deviations are one customary way to assess construct differentiation. The differentiation measure was obtained by calculating the standard deviation of ratings for each value construct. An average score was used to indicate the overall construct differentiation. Test-retest reliability (2 weeks), based on 14 university students, was .73 (Mau, 1997).

Number of occupations. This measure was assessed by counting the total number of occupations listed by participants in the Career Grid. Participants were instructed to list up to 10 occupations that they might like to enter regardless of training or education.

Program Satisfaction Questionnaire. Students' satisfaction with the program was measured based on a questionnaire composed of 10 statements (see Table 2). Items were derived from several studies, including Zener and Schnuelle (1972), Ryan and Drummond (1981), and Mau and Jepsen (1992). Students rated each of the 10 statements using a 5-point Likert scale (from 1, strongly disagree, to 5, strongly agree). For the first eight statements, a high rating ( 3 and above) indicated a positive reaction to the pro-gram utilized; for the last two statements, a high rating indicated a negative reaction toward the program. Satisfaction was defined by a composite score and/or each item score. The alpha coefficient estimated for this sample was .76.

\section{Results}

A multivariate analysis of covariance (MANCOVA) was first performed prior to a serial univariate analyses. Three dependent measures listed for analysis were construct integration, construct differentiation, and number of occupations chosen. The dependent variables were adjusted for the time participants spent on the treatment program as a covariate in the analysis. This was done because the length of treatment is a significant factor in career interventions (Mau, 1995; Mau \& Jepsen, 1992; Oliver \& Spokane, 1988). Although there was no significant difference in the average length of the treatments, participants varied in the amount of time they spent on the treatment programs. The use of covariate analysis should increase measurement precision. Results of the two-way 4 (treatment) $X 2$ (gender) MANCOVA indicated significant main effects for treatment, $F(9,312)=2.66, p<.005$, and gender, $F(3$, $102)=3.00, p<.034$. Neither two-way interaction, $F(9,312)=.49, p<.883$, nor time covariate, $F(3,102)$ $=2.44, \mathrm{p}<.068$ was significant.

Table 1

Means, Standard Deviations, and Summary of F-Tests, by Treatment s and Gender

\begin{tabular}{|c|c|c|c|c|c|c|c|c|c|c|}
\hline Variables & $\begin{array}{c}\text { VCS } \\
(n=31)\end{array}$ & $\begin{array}{c}S D S \\
(n=28)\end{array}$ & $\begin{array}{l}\text { SIGI+ } \\
(n=31)\end{array}$ & $\begin{array}{l}\text { Control } \\
(n=31)\end{array}$ & $\begin{array}{c}\text { Male } \\
(n=55)\end{array}$ & $\begin{array}{c}\text { Female } \\
(n=66)\end{array}$ & Treatment & $\begin{array}{l}\text { F-test } \\
\text { Gender }\end{array}$ & $T \times G$ & Contrast \\
\hline \multicolumn{11}{|c|}{ Construct Integration } \\
\hline$M$ & 11.2 & 11.4 & 14.8 & 17.1 & 13.5 & 13.6 & $5.53^{* * *}$ & .32 & .16 & $4>1,2$ \\
\hline$S D$ & 4.9 & 5.3 & 7.4 & 7.4 & 6.5 & 6.9 & & & & \\
\hline \multicolumn{11}{|c|}{ Construct Differentiation } \\
\hline$M$ & 4.8 & 5.1 & 4.8 & 4.7 & 5.2 & 4.5 & .61 & $7.48^{* *}$ & .70 & $M>F$ \\
\hline$S D$ & 1.9 & 1.5 & 1.5 & 1.5 & 1.5 & 1.6 & & & & \\
\hline \multicolumn{11}{|c|}{ No. of Occupations } \\
\hline$M$ & 6.9 & 7.1 & 6.6 & 4.5 & 6.2 & 6.4 & $7.47 * * *$ & .01 & .13 & $1,2,3>4$ \\
\hline$S D$ & 2.3 & 2.2 & 2.8 & 2.1 & 2.4 & 2.7 & & & & \\
\hline \multicolumn{11}{|c|}{ Time Spent on Treatment } \\
\hline$M$ & 78.6 & 73.9 & 73.6 & - & 73.3 & 69.9 & 1.18 & 2.99 & 1.47 & \\
\hline$S D$ & 10.7 & 15.2 & 15.9 & - & 18.0 & 13.3 & & & & \\
\hline \multicolumn{11}{|c|}{ Treatment Satisfaction } \\
\hline$M$ & 45.2 & 45.0 & 43.4 & NA & 43.6 & 45.2 & 1.59 & 1.58 & .54 & \\
\hline$S D$ & 3.2 & 5.1 & 2.7 & NA & 4.3 & 4.1 & & & & \\
\hline
\end{tabular}

Note. VCS (1): Vocational Card Sort; SDS (2): Self-Directed Search; SIGI+ (3): System of Interactive Guidance and Information Plus; Control (4): wait-listed control.

${ }^{* *} p<.01 ; * * * p<.001$. 
To understand the nature of these effects, univariate analyses of variance (ANOVA) were performed along each of the three dependent measures. Means and standard deviations for each of the conditions are shown in Table 1. Results indicated significant differences in construct integration among the four groups, $F(3,112)=5.53, p<.001$. Members of the VCS $(M=11.2)$ and SDS $(M=11.4)$ groups showed significantly lower integration scores than those of the control group $(M=17.1)$. Members of the $\mathrm{SIGI}+(\mathrm{M}=14.8)$ group also scored lower than those of the control group on construct integration but not at a significant level. Results also indicated significant gender differences in construct differentiation, $F(1$, $112)=7.48, p<.013$. Male participants $(M=5.2)$ showed significantly higher differentiation scores than those of female participants $(M=4.5)$. Another significant treatment difference was found regarding the number of occupations chosen, $F(3,120)=7.47, p<.001$. All treatment groups (VCS: $M=6.9$; SDS: $M=$ 7.1; $\mathrm{SIGI}: \mathrm{M}=6.6$ ) showed a significantly greater number of occupations chosen than those of the control group $(M=4.5)$. No significant gender differences were found regarding the number of occupations chosen.

Students' overall satisfaction was first analyzed using two-way ANOVAs, with the total score as a dependent variable. Results indicated no significant differences based on treatment, $F(2,69)=1.59, p<$ .19 or gender, $F(1,120)=1.58, p<21$. Table 2 lists means and standard deviations of treatment satisfaction, by treatment and item.

\section{Discussion}

In this study, career interventions had a direct impact on the voca-tional cognitive complexity of students engaged in the process of career decision-making. Overall, regardless of the treatment type, all three interventions substantially decreased integration scores. It is very important that one interprets the results in the context of a vocational cognitive developmental model. Although advanced cognitive development is characterized by high construct integration and differentiation, a decrease in integration should not be interpreted as a regression in vocational cognitive development. According to Neimeyer (1988), the loosening of vocational constructs is necessary for individuals to move toward a higher level of cognitive development. Because this sample consisted of college freshmen, who are typically in an exploratory stage of career development, the decrease in construct integration scores can best be characterized as the movement from stage 2 (low construct differentiation and high construct integration) into stage 3 (high construct differentiation and low con-struct integration) of Neimeyer's (1988) four-stage structural model discussed earlier.

The assumption that value-based treatments (VCS and SIGI +) would have a greater impact on construct integration than the non value-based treatment (SDS) was only partially supported. Not only VCS and SIGI + had a significant impact on construct integration, SDS also yielded a significantly higher integration score than that of the control group on this measure. The lack of differential effect among treatments, however, was consistent with previous literature reviews (e.g., Fretz, 1981; Holland, Magoon, \& Spokane, 1981), suggesting that most career interventions result in a small but similar impact, regardless of the treatment type.

Although SIGI + yielded a lower integration score than that of the control group, its impact was not statistically significant. Research (Moore, Neimeyer, \& Marmarosh, 1992) has indicated that vocational constructs are "loosened" upon exposure to information that disconfirms previous career perceptions. It is likely that because SIGI + is an information-oriented intervention, the overall impact of this intervention on construct integration may have been "washed out" with individuals who received information that confirmed and/or disconfirmed prior occupational perceptions.

As expected, both the VCS and SDS groups significantly increased occupational options compared to the control group. Previous research has consistently indicated that VCS (e.g., Cooper, 1976; Slaney \& Dickson, 1985) and SDS (Krivatsy \& Magoon, 1976; Takai \& Hol-land, 1979; Talbot \& Birk, 1979) are effective in stimulating a greater number of vocational options. SIGI + also significantly increased 
occupational options for students compared to the control group. Therefore, all three treatment programs appeared to be capable of increasing vocational options. This outcome also held true for both men and women, suggesting that the three interventions were equally effective in stimulating vocational options regardless of gender.

Table 2

Means, Standard Deviations of Treatment Satisfaction by Items and Treatment Programs

\begin{tabular}{|c|c|c|c|c|c|c|}
\hline \multirow[b]{2}{*}{ Items } & \multicolumn{2}{|c|}{ VCS } & \multicolumn{2}{|c|}{ SDS } & \multicolumn{2}{|c|}{ SIGI+ } \\
\hline & M & $S D$ & $M$ & $S D$ & $M$ & $S D$ \\
\hline 1. This program session was fun. & 4.3 & .7 & 4.3 & .6 & 4.0 & 1.0 \\
\hline $\begin{array}{l}\text { 2. This program session helped me to further engage myself in self } \\
\text { exploration. }\end{array}$ & 4.5 & .7 & 4.6 & .6 & 4.3 & .6 \\
\hline $\begin{array}{l}\text { 3. This program session helped me to further engage myself in career } \\
\text { exploration. }\end{array}$ & 4.6 & .6 & 4.6 & .6 & 4.3 & .7 \\
\hline $\begin{array}{l}\text { 4. This program session helped me in making the educational/vocational } \\
\text { decisions. }\end{array}$ & 3.6 & 1.0 & 3.8 & .9 & 3.6 & 1.2 \\
\hline $\begin{array}{l}\text { 5. The instructions provided for this program session were easy to follow. } \\
\text { 6. The information presented in this program session was easy to under- }\end{array}$ & 4.8 & .4 & 4.9 & .3 & 4.5 & .3 \\
\hline stand. & 4.8 & .4 & 4.9 & .3 & 4.6 & .8 \\
\hline 7. I felt comfortable during the program session. & 4.8 & .4 & 4.8 & .4 & 4.7 & .5 \\
\hline $\begin{array}{l}\text { 8. I will recommend that my friends use this program session. } \\
\text { 9. I was confused about my educational/vocational plans after participating }\end{array}$ & 4.6 & .8 & 4.4 & .8 & 4.4 & 1.0 \\
\hline in this program session. & 4.2 & 1.2 & 4.1 & 1.1 & 4.3 & 1.1 \\
\hline 10. Using this program session was a waste of time. & 5.0 & .2 & 4.7 & .7 & 4.8 & .5 \\
\hline
\end{tabular}

Note. Scores were based on a 5-point Likert rating scale from 1, strongly disagree, to 5, strongly agree. Scores for Items 9 and 10 were reversed.

Consistent with previous research findings (Bodden, 1970; Neimeyer, 1988; Neimeyer, Metzler, \& Bowman, 1988), the present study also indicated a significant difference between men and women in the construct differentiation. The findings of this study indicated no differential treatment impact on men and women. Irrespective of interventions, men scored significantly higher than women on construct differentiation. Although the three interventions had a significant impact on construct integration, there is no differential impact on gender. The lack of treatment and gender interaction suggested that both men and women can benefit from career interventions in terms of construct integration.

The present study showed that students were very positive about the treatment programs overall. The findings do not indicate that stu-dents favored VCS over SDS or SIGI + in regard to the level of counselor involvement. This may indicate that computer applications are increasingly gaining acceptance among a younger population, which has frequent exposure to computer technology. Men and women did not differ in their perceived satisfaction with the treatments; therefore, these career intervention programs were equally liked by men and women.

\section{Implications}

Several implications for counseling can be made based on the find-ings of this study. Given the characteristics of the sample, the results of this study may be generalizable to similar groups of careeroriented college students. Counselors often have to choose among different instruments for career interventions that match clients' career developmental level and the types of career issues. College freshmen are typically in a stage of career exploration in which the restructuring of vocational constructs is critical. This study found that career interventions can significantly enhance students' career development, especially in the area of the construct integration. Since treatment impact was not found to be gender dependent, these three career interventions are equally useful for male students and female students. 
Since the three treatments were approximately equally effective in facilitating construct integration and in stimulating more occupational options, the counselor's time and material costs become important factors in the selection of instruments used for intervention. Compared to SIGI+ and SDS, VCS is the least expensive in terms of material and equipment costs, but requires more of the counselor's time. Although $\mathrm{SIGI}+$ is relatively more expensive to implement, it can free counselors to do other counseling activities, and therefore it may be more cost-effective in the long run. SDS is a reasonable choice for counselors who have smaller budgets to work with, since it is less expensive to implement than SIGI+ and demands fewer human resources than VCS. Nevertheless, the choice of one instrument should not exclude another.

In summary, the three intervention programs were found to be effective in facilitating vocational cognitive development, especially construct integration, of college students as measured by the Career Grid procedure. Counselors need to be aware of gender differences as well as individual differences in vocational cognitive complexity. Understanding how an individual progresses through the stages of vocational cognitive development is crucial in order for counselors to evaluate the effectiveness of those strategies. Neimeyer's (1988) vocational cognitive development model may be used to evaluate and monitor students' progress through the various stages of vocational cognitive development.

Since there are very few studies examining the effect of different career interventions on vocational cognitive complexity, the conclusions of this study are tentative. Several limitations of this study should be noted. First, the small size of treatment effects needs to be considered when interpreting the results. The short treatment length may have minimized the size of treatment effects. Second, the structural model used to understand the effect of career interventions has not yet been validated. Research attention has not yet adequately addressed the independence of construct differentiation and integration (Neimeyer, 1988). Further studies are needed to expand and clarify the findings of this study. In particular, longitudinal or cross-sectional studies can advance our current understanding regarding the effect of career interventions on the different stages of vocational cognitive development.

\section{References}

Adams-Webber, J. (1979). Personal construct theory: Concepts and applications. New York: Wiley.

Bodden, J. (1970). Cognitive complexity as a factor in appropriate vocational choice. Journal of Counseling Psychology, 17, 364-368.

Bodden, J., \& Klein, A. (1972). Cognitive complexity and appropriate vocational choice: Another look. Journal of Counseling Psychology, 19, 257-258.

Brook, J. (1992). Use of the repertory grid in career counseling. The Career Development Quarterly, 41, 39-50.

Chambers, W., \& Grice, J. (1986). Circumgrids: A repertory grid package for personal computers. Behavior Research Methods, Instruments, and Computers, 28(5), 468.

Cochran, L. (1983). Seven measures of the ways that deciders frame their career decisions. Measurement and Evaluation in Guidance, 16(2), 67-77.

Cooper, J. (1976). Comparative impact of the SCII and the Vocational Card Sort on career salience and career exploration of women. Journal of Counseling Psychology, 23, 348-352.

Dolliver, R. (1967). An adaptation of the Tyler Vocational Card Sort. Personnel and Guidance Journal, 45, 916-920.

Educational Testing Service (1994). System of Interactive Guidance and Information. Princeton, NJ: ETS.

Feixas, G., Moliner, J. L., Montes, J. N., Mari, M. T., \& Neimeyer, R. A. (1992). The stability of structural measure derived from repertory grid. International Journal of Personal Construct Psychology, 5, 25-37.

Fretz, B. R. (1981). Evaluating the effectiveness of career Interventions. Journal of Counseling Psychology Monograph, 28, 77-90. 
Holland. J. (1985). Making vocational choices. A theory of vocational personalities and work environments. (2nd ed.) Englewood Cliffs, NJ: Prentice-Hall.

Holland, J., (1994). Self-Directed Search, Form R (4th ed). Odessa, FL: Psychological Assessment Resources. Holland, J. L., Magoon, T. M., \& Spokane, A. R. (1981). Counseling psychology: Career interventions, research and theory. Annual Review of Psychology, 32, 279-305.

Kortas, L. Neimeyer, G . \& Prichard, S. (1992). Structure and style in career decision making. Journal of Career Development, 18, 199-214.

Krivatsy, S. E. \& Magoon, T. M. (1976). Differential effects of three vocational counseling treatments. Journal of Counseling Psychology, 28, 315-320.

Landfield, A., \& Schmittdiel, C. (1983). The interpersonal transaction group: Evolving measurements in the pursuit of theory. In J. R. Adams-Webber \& J. C. Mancuso (Eds.). Applications of personal construct theory (pp. 207-218). Toronto: Academic Press.

Landfield, A. W. (1977). Interpretive man: The enlarged self-image. Nebraska Symposium on Motivation, 1976. Lincoln: University of Nebraska Press.

Mau, W C. (1997). Assessing the Cognitive Complexity of Vocational Value Constructs Using the Career Grid: A Comparison of the Expressed and Supplied Methods. Measurement and Evaluation in Counseling and Development, 29, 202-214.

Mau, W. C. (1995). Decision-making style as a predictor of career decision-making status and treatment gains. Journal of Career Assessment, 3, 89-99.

Mau, W. C., \& Jepsen, D. A. (1992). Effects of computer-assisted instruction in using formal decisionmaking strategies to choose a college major. Journal of Counseling Psychology, 39, 185-192.

Moore, M. A., Neimeyer, G. J., \& Marmarosh, C. (1992). Effects of informational valence and occupational favorability on vocational differentiation: A test of the disconfirmation hypothesis. Journal of Counseling Psychology, 39, 335-341.

Neimeyer, G. (1988). Cognitive integration and differentiation in vocational behavior. The Counseling Psychologist, 16, 440-475.

Neimeyer, G., Metzler, A., \& Bowman, R. (1988). The effects of sex, career orientation, and occupational type on vocational integration, differentiation, and conflict. Journal of Counseling Psychology, 35, 139-143.

Neimeyer, G. Nevill, D., Probert, B., \& Fukuyama, M (1985). Cognitive structures in vocational development. Journal of Vocational Behavior, 27, 191-201.

Nevill, D , Neimeyer, G., Probert, B., \& Fukuyama, M. (1986). Cognitive structures in vocational information processing and decision making. Journal of Vocational Behavior, 28, 110-122.

Oliver, L. W., \& Spokane, A. R. (1988). Career-intervention outcome: What contributes to client gain? Journal of Counseling Psychology, 35, 447. 462.

Parr, J., \& Neimeyer, G. (1994). Effects of gender, construct type, occupational information, and career relevance on vocational differentiation. Journal of Counseling Psychology, 41, 27-33.

Ryan, CW, \& Drummond, R. J. (1981). Differential impacts of a computer information system on selected human service agencies. AEDS Journal. 14, 73-83.

Slaney, R., \& Dickson, R. (1985). Relation of career indecision to career exploration with reentry women: A treatment and follow-up study. Journal of Counseling Psychology, 32, 355-362

Slater, P. (1977). Dimensions of intrapersonal space. New York: Wiley.

Sewell, K. W., Milterer, J., Adams-Webber, J. Cromwell, R. L. (1991). Omnigrid-PC: A new development in computerized repertory grids. International Journal of Personal Construct Psychology, 4, 175-192.

Takai, R., \& Holland, J. (1979). Comparison of the Vocational Card Sort, the SDS, and the Vocational Exploration and Insight Knit. The Vocational Guidance Quarterly, 27, 312-318.

Talbot, D., \& Birk, M. (1979). Does the vocational exploration and insight kit equal the sum of its parts?: A comparative study. Journal of Counseling Psychology, 26, 359-362. 
Tiedeman, D. V., \& O'Hara, R. P. (1963). Career development: Choice and adjustment. New York: College Entrance Examination Board.

Werner, H. (1957). The concept of development from a comparative and organismic point of view. In D. B. Harris (Ed.), The concept of development. Minneapolis: U Diversity of Minnesota Press.

Winer, D., \& Gati, I. (1986). Cognitive complexity and interest crystallization. Journal of Vocational Behavior, 28, 28-59.

Zener, T., \& Schnuelle, L. (1972). An evaluation of the Self-Directed Search: A guide to educational and vocational planning (Research Report No. 124). Baltimore: Johns Hopkins University, Center for Social Organization of Schools (ERIC Document Re-production Service No. ED 061 458). 